\title{
Notas sobre las melancolías y las perezas en La mafia rusa, de Daniel Link
}

2. CRISTIAn Molina / Universidad Nacional de Rosario - CONICET / molacris@yahoo.com.ar

\section{Resumen}

El presente trabajo sobre los relatos de mercado en Daniel Link y sus relaciones con el mercado en el siglo Xxi es parte de uno mayor respecto del problema en el Cono Sur. Aquí exploro los matices que adquiere la melancolía y la pereza en La mafia rusa de Daniel Link, así como el uso del blog en tanto dispositivo de circulación que pone en juego una heterocronía temporal contemporánea melancólica. Por ende, me detengo en los sentidos que adquiere la melancolía en la máquina narrativa de Daniel Link, y en las implicancias que esa multiplicidad conlleva en diversos niveles. La hipótesis que sostengo es que así como existen múltiples melancolías en Link, hay algunas que adquieren una positividad vital: sobre todo aquellas que las reivindican como formas de supervivencia futura del pasado en el presente a partir de fantasmagorías que aparecen en las ficciones. Estos sentidos de la melancolía se articulan además con la pereza como una forma activa de la misma que revela disonancias con el mercado. Por último, las propias circulaciones entre el blog, la red y el libro revelan un dispositivo perezoso y melancólico de intervención que desestabiliza los valores (económicos y simbólicos) del mercado en el que circulan.
Palabras clave: melancolía $\cdot$ mercado $\cdot$ pereza $\cdot$ libro $\cdot$ blog

\section{Abstract}

The present work on the melancholy and laziness in Daniel Link and their relations with the publishing market in the $s$ xxI is a part of a larger problem than the one in South America. Here I explore the nuances that melancholy and laziness acquires in La mafia rusa by Daniel Link, as well as the melancholy and laziness's use of the blog as a circulation device, which put a stake a contemporary temporal heterochrony. Therefore, I stop at the meanings that melancholy takes in the narrative machine of Daniel Link, and in the implications that that multiplicity leads to, at all levels. The hypothesis that I sustain is that such as there are multiple melancholy in Link; there are some that acquire a vital possibility: most of all those who are vindicate as survival ways from the past in the present starting from the phantasmagoria that appears in fiction. These meanings of melancholy are articulated besides, with the sloth as an active way of itself that reveals dissonances with the market.At last, the mere circulations between the blog, internet and the book; reveal a lazy and melancholy intervention device that 
put out of balance the values (economic and Key words: melancholy • publishing market • laziness • symbolic) of the market in which they circulate. book $\cdot$ blog

\section{Insistencias}

Desde que decidí leer sobre los posibles avatares de la melancolía y de la pereza como relaciones aún insistentes con el mercado en el siglo XXI, comencé a sufrir (el cuerpo que escribe) varios de sus síntomas. En aumento. Pareciera que, muchas veces, escribir sobre la melancolía y la pereza enfrenta al duelo anticipado de la escritura, un duelo que se intenta alejar frente a la inacción con la cual el cuerpo es sometido, paulatinamente, ante ese pathos o enfermedad sobre la que se lee y sobre la que se intenta escribir. Este escrito fue postergado hasta el hartazgo durante, al menos, dos años.

Volvía sobre los textos de Link con un entusiasmo y unas energías vehementes para escribir algo, avanzaba sobre las lecturas respecto de la melancolía y de la pereza que me podían ayudar, siquiera preliminarmente, a esbozar un párrafo y caía, de inmediato, bajo la impotencia y el desgano. No soy de esos a quienes les cuesta escribir. Diría que todo lo contrario: aquello que cuesta es abandonado por una flojera debido a la pérdida de intensidad que presupone su prolongación indefinida. Sin embargo, no fue este el caso. Por primera vez, las novelas y ensayos de Daniel Link a los que regresaba se expandían en significados contrapuestos en cada lectura hasta convertirse, muchas veces, en mutantes y, por eso mismo, inaprensibles para cualquier generalización lineal de la lectura.

Y, particularmente, la melancolía y la pereza eran dos de esas palabras que no sólo atravesaban con una notable presencia todas sus novelas y relatos, sino, además, sus producciones ensayísticas. Todos los personajes de sus novelas y algunos de los relatos La mafia rusa - sobre la cual me concentraré- son constitutivamente o convertidos en melancólicos y perezosos. Así, en los años 90, en la carta al hijo que escribe Manuel en el capítulo «I999", éste sostiene que su hija muerta se ha convertido en una presencia que produjo un desequilibrio imaginario que pierde, no la «lengua o la escritura», sino «la ficción»; por lo cual, el personaje intenta reparar esa pérdida en un viaje imaginario permanente. De este modo, se entrega a la escritura de un diario para «perder el tiempo: llenar el tiempo». Ese duelo imposible que genera sustitutos que alteran el tiempo, no es sino, como sabemos, una de las caras de la melancolía.

En la tradición occidental, la melancolía está ligada al desarreglo del tiempo. Ya Robert Burton sostenía que una de las principales afecciones del melancólico era la memoria, por formar parte de la imaginación que se altera. También las lecturas que realiza Walter Benjamin de la experiencia baudelaireana, articulada entre el duelo y el shock ante la ciudad mutante de París que activa la memoria voluntaria e involuntaria en el paseo del flâneur, dan cuenta de esa temporalidad alterada que los melancólicos trasladan a su escritura. Incluso en el psicoanálisis, en el texto inaugural, "Duelo y melancolía», de Sigmund Freud, la misma se 
define como la imposibilidad de elaborar un duelo en el presente por un objeto de deseo perdido (muerto) en el pasado. Entonces, si es una actitud ante una pérdida pasada que permite retener en la historia del sujeto el deseo del objeto o el objeto de deseo en un plano imaginario, siempre implica una relación temporal: se intenta recuperar algo que ha muerto, que ya no es en el presente y, que, por ende, pertenece al pasado, pero que insiste abriendo su futuro.

Así, la melancolía es una actitud que sostiene algo muerto de un pasado - o algo del pasado - en el presente, paradójica y contradictoriamente, pero que en todo caso hace que ese pasado continúe, aunque transformado y, por lo tanto, abierto a su supervivencia futura, en un pleno devenir melancólico como una deriva de fantasmas que siguen siendo y que harán seguir siendo sin ser a ese objeto/ deseo sobre el que ha recaído la imposibilidad del duelo a pesar de su muerte.

De modo que la melancolía implica un desajuste temporal ante un duelo intempestivo que no se puede realizar. De esta manera, desprendo de la actitud melancólica una carga meramente regresiva - o negativa - y la entiendo como una actitud sobre el tiempo desde la consciencia de la muerte del tiempo que permite la supervivencia y las reelaboraciones alternativas del futuro de un pasado en el presente en el que ese pasado ya no podría tener lugar. Es, en este sentido, antes que una detención, una nostalgia o una angustia ante la muerte del tiempo, una manera de supervivencia alternativa ante la negación del duelo del tiempo.

Es por esto que, en Los años 'oo, la melancolía pone en movimiento la escritura del diario para conjurar la pérdida de la ficción que implica la muerte de la hija y que somete al narrador a una pérdida de tiempo, a un estado de pereza extrema. También en La ansiedad, Manuel, después de haber perdido a su chongo francés, se confiesa no sólo melancólico, sino, además, perezoso. Y en Montserrat, la melancolía como ruina esplendorosa de un pasado que persiste fantasmagóricamente en el barrio y que somete al escritor, también llamado Manuel, a un ritmo bulímico entre la pereza y la superproducción para sobrevivir en un mundo de "pobreza» y capitalismo, es evidente. Tanto en Fantasmas, como así también en Cómo se lee, las palabras melancolía y pereza, sobre todo en el primero, saturan la escritura de Link con una enorme presencia.

Sin embargo, sería simplificador afirmar que Link es melancólico y perezoso en sus relaciones con el mercado por la mera presencia en la superficie textual de esas palabras en una proliferación desbordante que tiende a marcar una relación con el mercado de sus protagonistas escritores. Al contrario, como ha señalado Jean Starobinski a propósito de Baudelaire, la melancolía pocas veces — si no nuncase enuncia como tal en la escritura espejada del melancólico. De modo que, ante esa alternativa, afirmar o negar la melancolía o la pereza en Link por el uso de esas palabras en la escritura resulta, cuanto menos, sospechoso. Antes conviene, por el contrario, leer si esas palabras adquieren o no mutaciones y modulaciones en algunos momentos de su escritura y ver qué sucede allí: si esa escritura se sostiene, efectivamente, en una relación melancólica o, por el contario, sólo simula y coquetea con esta tradición, muchas veces, para impugnarla. 


\section{Melancolías}

Para acercarme, siquiera desde su lejanía, a lo que sucede con el avatar de la melancolía en Link me ayudó la lectura de Fantasmas (2009b), porque en ese libro se condensan con precisión dos de los sentidos que, en su narrativa, son alternados. Desde el inicio del libro, Link fija una posición al respecto, cuando discurre sobre la imaginación como una categoría negada reactivamente por la teoría contemporánea. En «Cartas», la melancolía adquiere dos valores contrapuestos que son, a su vez, dos modos de entenderla. En la carta a su "querido Jorge» ¿Giorgio Agamben? ¿Panesi?), escribe: «¿Pero, entonces? ¿Qué nos queda? Cualquier cosa, muchas cosas, pero en todo caso no la melancolía por los tiempos idos. La comunidad que viene» (2009b:45). Frente a la repulsión del presente y dentro del pesimismo ante una cultura entendida como encarnación del mal absoluto, la melancolía por los tiempos idos no es una opción. Se trata, como vemos, de desligarla de una concepción esquemática e intuitiva, casi un lugar común de la melancolía, entendida en términos de añoranza, de un páthos romántico que cosifica el pasado como un pasado mejor e inaccesible al que habría que volver. Entonces, para Link, ese tipo de melancolía no ofrece ninguna alternativa.

Hasta nos veríamos tentados a quedarnos con esa negación de la melancolía como única respuesta, si no advirtiéramos que, apenas unas páginas después, la melancolía adquiere otro valor como alternativa:

I. La imaginación humanista considera al tiempo como una continuidad entre pasado, presente y futuro. Tal vez sea eso lo que hoy nos impone como imposible (quejas benjaminianas y hobsbawnianas ante la pérdida de referencia de las tradiciones). Entonces, nos encontramos con posiciones del tipo no future (no hay futuro). Nihilismo, depresión, melancolía, nostalgia: unidades de la imaginación de la catástrofe. (65)

Esta cita la introduce luego de preguntarse qué nos queda si ya el humanismo y el poshumanismo son insostenibles. Así, responderá que quedan otros imaginarios. Uno de ellos es la imaginación de la catástrofe, que presupone la consciencia de una aniquilación intempestiva e involucra, antes que una linealidad, la posibilidad de atravesar estratos temporales diferentes como una empresa, sostiene Link, de abolición del lenguaje a partir de una potencia indefinida que fundaría su singularidad. La imaginación de la catástrofe, entonces, es un puro devenir donde se muestra no la máscara, sino la fuerza, el páthos y la potencia de lo real como desastre que advendrá, pero que aún no ha ocurrido. Pero esa imaginación está ligada, como vimos, a la melancolía, y a una constelación de términos: nihilismo, depresión, nostalgia. La melancolía aparece, aquí, lejos de la negación que presuponía en el otro uso - o devenir — por la escritura, como una potencia de la imaginación de la catástrofe, plausible de atravesar diferentes estratos temporales y de generar una singularidad de la escritura que avance hacia la comunidad que vendrá. ${ }^{1}$ Aquí, la melancolía, dentro del imaginario de la catástrofe, es una potencia de futuro ante la muerte del presente que se convierte, así, en pasado futuro. 
Y si sospechamos que la carta puede dialogar, en referencias, pero incluso, en el destinatario, con Giorgio Agamben, no podemos olvidar el vínculo que el filósofo italiano mantiene entre imaginación y melancolía en su libro Estancias. ${ }^{2}$ Cuando revisita la definición psicoanalítica de melancolía, recurriendo a la teoría del fantaseo y del fantasma, Agamben sostiene que la melancolía en Freud es un desequilibrio imaginario que intenta recuperar un objeto de deseo perdido con una proliferación de fantasmas. Una insistencia prepotente de la imaginación que fantasea - y por lo tanto, nunca llega a - la recuperación de un objeto perdido mediante la instauración de un duelo incesante. Slavoj Žižek sostiene que lo que la melancolía genera son sustitutos imaginarios que ofician materializando no el objeto de deseo perdido, sino el deseo perdido por el objeto. Tanto en una como en otra perspectiva, la melancolía genera imaginación y fantaseo, y se sostiene en una pérdida que es vivida como desastre o catástrofe incesante, indefinida, que no pasa, porque no se puede asumir el duelo. Pero si hay pérdida, se entabla, entonces, un desequilibrio que es imaginario y temporal. Las estratificaciones temporales en esos sustitutos se cruzan y se conflictúan. Lo perdido — objeto/deseo-corresponde a un estrato que no se quiere pasado, sino que se trae al presente para su supervivencia futura. De ahí que la melancolía no se pueda confundir, aunque guarde una relación sintomática, con la mera añoranza. La melancolía es una potencia de supervivencia que genera una densa estratificación temporal e imaginaria, lejos de la linealidad humanista del tiempo. En la imaginación melancólica lo que está roto es, justamente, la continuidad lineal entre pasado, presente y futuro: los tres se dan al mismo tiempo. Y en este sentido, como proliferación de fantasmas y de sustitutos, al libro de Link, titulado justamente Fantasmas, podemos pensarlo como un juego entre la multiplicación del sentido sobre determinadas palabras que aparecen, insistentes, como ruinas (melancolía, pop, catástrofe, nihilismo, etc.) que evita simultáneamente el duelo de algunas de ellas en una fantasmagoría melancólica que los hace devenir con significados determinados en su indeterminación.

Los dos sentidos de la melancolía que hemos leído en Fantasmas, reaparecerán en sus producciones ficcionales previas. De ahí que no podamos sostener que las ficciones son una puesta en juego de aquello que en el orden ensayístico se explora, sino que, como advierte Javier Gasparri, se va creando una sinergia entre la producción ensayística y ficcional que genera la impresión de una escritura viviente que avanza sobre tópicos, formas y mutaciones, cíclicamente, en niveles de complejidad cada vez mayores y proliferantes. Y si es que de vida y literatura se trata, la escritura de Link no es tanto una escritura sobre la vida, sino una escritura viviente que crea sus propios mecanismos de vida como forma: puro exceso. ${ }^{3}$ La vida, como señalan Giorgi y Rodríguez, presupone la muerte y, por lo tanto, habilita o no, un duelo incesante, cíclico, que abre la posibilidad de la melancolía. De una escritura viviente y melancólica que, en sus ficciones, se precipita, además, como escritura viviente de vidas melancólicas.

Queda claro, entonces, que la redefinición de melancolía en Link —y la que nos interesa a nosotros - no es la que ha consagrado el sentido añorante, sino 
que se remite a la complejidad que esta tradición abre desde el «Problemata Xxx» de Aristóteles sobre la misma. En el mismo, la melancolía es una afección anímico-corporal producto del equilibrio de la bilis negra en el sistema de los humores. Pero adquiere sentidos oscilantes, no sólo en cuanto a los caracteres y síntomas que puede generar, sino a los estados de quienes la padecen. Así, Aristóteles sostenía que la melancolía produce diversos caracteres según la mezcla individual de los humores con la bilis negra. Si había un exceso de bilis negra fría, el carácter melancólico se volvía torpe y estúpido. Si, en cambio, éste era caliente, los melancólicos podían ser exaltados, brillantes, eróticos, o prestos a la ira, al deseo sexual o a la locuacidad. Mientras que, también, se podía dar el caso de un término medio entre esos excesos que generaría la genialidad de quien la padece. De modo que, para Aristóteles: «El temperamento melancólico, así como produce enfermedades de variación, es en sí mismo variable, pues como el agua unas veces frío y otras caliente» (49). Lo que esa tradición instaura, es el carácter complejo y múltiple de la melancolía, que, en Ritvo, será definida, por esto mismo, como un pasaje entre extremos que se presentifica en la escritura; es decir, un discurso de la interrupción. Lo que me interesa señalar es, además, cómo desde Aristóteles, esos extremos adquieren, además, una oscilación contradictoria y diferencial, ya que si bien la melancolía es una afección muchas veces negativa del estado anímico, en el caso de la genialidad, puede constituir una afección saludable y positiva. La melancolía convoca, entonces, desde Aristóteles, el espacio ubicuo de las oscilaciones, muchas veces contradictorias.

No es esto sino lo que acontece con la melancolía de los personajes de los relatos de La mafia rusa. Se trata, en la mayoría de los casos, de vidas melancólicas puestas en un paréntesis de inacción que, sin embargo, generan acción, a veces, como relato o como escritura. En "Yo fui un niño de ocho años», la escritura pone en movimiento el fantaseo sobre un momento puntual: el de la pérdida de la infancia. Se trata de imaginar ese momento que se considera olvidado. Pero lejos de tratarse de una mera operación de memoria, la escritura, como en Proust, hace vivir ese momento, generando la supervivencia como invención. De lo que se trata, entonces, es de la puesta en juego del intento de recuperación de la infancia como el momento en el que se pierde, pero para volver a perderla; es decir, para no perder nunca el momento en el cual se pierde. No obstante, esa pérdida no es sino algo que «imagino», sostiene el narrador en el final de "Yo fui pobre». Por ende, cuando el narrador recurre a una infancia de carencias relativas, no lo hace sino para vivirlo imaginariamente. ${ }^{4}$ No importa la pobreza o no de la infancia, importa volver inventar el momento de su pérdida y esa invención es la de una pobreza originaria en este caso.

Sin embargo, otra melancolía aparece también en «Yo fui un niño de ocho años»:

Pregunté, con curiosidad malsana, cuánto valían esos animales que en algún momento de mi vida perdí de vista y que ahora añoraba de pronto, al tenerlos de nuevo frente a mí. Los precios oscilaban entre los 20 y los 50 oiros (como se dice en lengua áspera que yo usaba por entonces). 
Sólo mis elefantes, jirafas y leones, si hoy los conservara, valdrían en un mercado de pulgas de Berlín, poco más de 300 oiros. Mi colección completa, calculé con pena, podría venderse (si es que hubiera un comprador tan melancólico como el que se requería) a una suma por lo menos tres veces superior, digamos: un pasaje a Europa en baja temporada. (Link 2008:56)

Es la melancolía posible de un comprador añorante capaz de recuperar el deseo por esos juguetes compartidos que siguen estando en las ruinas del mundo, de un mercado de Berlín, aunque ya no estén en la vida de los adultos que rememoran la infancia. Es, entonces, una melancolía que detiene al narrador sin devenir él mismo un comprador, sin obtener esos juguetes que se saben idénticos a los perdidos. Los juguetes son una supervivencia cosificada del pasado en la ruina de la vida adulta. Por eso, lo que importa es la suma de dinero, es decir, el valor económico de esos juguetes que están ahí como posibles sustitutos de la pérdida de la infancia. Una melancolía de los objetos que trae al presente un pasado, pero que el narrador abandona sin comprar, finalmente, seducido por su fantaseo, porque esos objetos son puro pasado. Y si esos objetos tienen alguna importancia, no es como pasado que perdura en las ruinas de una ciudad, sino como potencias para imaginar y fantasear el momento en que se deviene un "perverso dialéctico» y se pierde la infancia, otra vez.

Así, los dos sentidos contradictorios y opuestos que habíamos observado de la melancolía, como mero pasado que se añora, y el otro, como potencia de la imaginación, aparecen en "Yo fui un niño de ocho años» en una oscilación contradictoria que se pega y despega de dos tipos de melancolía diferentes: la de la mera imaginación humanista de recuperación del pasado mejor y la de la imaginación de la catástrofe, que sabe que, como el pasado ya no es, hay que imaginarlo como posible, tratando de recuperar mediante el fantaseo la fuerza de lo real, haciéndolo devenir en un futuro que se sabe ya, también, desastroso por su futura transformación en pasado, en mera ruina. En esta dirección, la melancolía genera un umbral de temporalidades. De este modo, cuando la melancolía se enuncia, entonces, lo hace como oscilación entre sentidos contradictorios: la melancolía es deseable sólo en tanto que imaginación futura del pasado en el presente; pero carece de potencia como rescate añorante de un pasado mejor y siempre idéntico, cosificador y reactivo, puesto a la venta en un mercado retro.

\section{Perezas}

La pereza articula, en Link, la melancolía con el mercado. Pero para entender esto, es necesario detenernos en "Parpadeos», el diario del escritor perezoso que se publica en La mafia rusa. ${ }^{5}$ Si esa articulación es posible, es porque, también, la pereza adquiere sentidos oscilantes a lo largo del relato. Es decir, la pereza tiene estructura de un parpadeo lento: cuando el ojo se abre, adquiere un valor y sentido, cuando se cierra, tiene otros. Y esos valores-sentidos están, claro, puestos en forma en el uso de las citas: la condena de la pereza por los versículos bíblicos o por los viajeros europeos, y la potencia política y estética de la pereza en la 
bibliografía que se cita $-\mathrm{y}$ rescribe- . Ese doble valor y sentido de una misma palabra, puede leerse en la siguiente frase de la entrada del diario del viernes 15 , a las I2: «Debería hacer de esta pereza patológica (si es que viene de mi acedia) o étnica (si es que sencillamente se debe a que soy argentino), una pereza moral, y por lo tanto política, es decir: revolucionaria» (2008:82).

¿Cómo leer esa frase si descansa en una ambigüedad aparentemente indiscernible? Creo que hay varios motivos para entender que, allí, diversos valores de la pereza se abisman para generar un valor más allá de cualquier moral y, por ende, indeterminado. Nuevamente, un umbral, pero ahora entre sentidos contradictorios y múltiples. Para dotar a la pereza de un valor que escapa a cualquier tipo de moral y, por lo tanto, de toda dicotomía axiológica. Por un lado, la pereza inmoral de la argentinidad como clisé racial europeísta que proviene, no casualmente, del diario de un evolucionista; pero adosada a la patologización moral de la pereza ligada a la enfermedad monacal de la acedia por la misma tradición cristiana. Digamos, se trataría de una pereza telúrico-racial y religiosa que descansaría en el discurso de la flojera como mal. De ahí las citas de la Biblia que se ponen en funcionamiento como condena de la pereza durante todo el diario. Sin embargo, esa fusión, esa aparición negativa de la pereza no hace sino enfatizar su positividad: la potencia política de la pereza que es correlativa de una potencia estética.

Porque la escritura en el diario sobre la pereza es parte de un trabajo solicitado por el editor de Latido para enfatizar su carácter revolucionario, fundado en el «derecho a no hacer nada». Lo que declara el diarista es que ha caído en un pozo de inactividad desde hace días. Pero con lo que se encuentra es con que no basta caer en la inactividad, simplemente, no hacer nada porque sí, sino preferir, como Bartleby, no hacerlo. Es decir, elegir no hacer nada como un proceso que conduce el deseo a desear la nada. Por eso, la pereza no es alegre para el diarista, sino feliz; es decir, es un estado permanente, no transitorio, ya que es revolucionario en tanto "forma activa de la melancolía, esa variación morbosa (y dulce) del luto, del duelo, de la pérdida» (Link 2008:68). Y esa forma activa es una forma menor, despreciada, incluso, por gran parte de las tradiciones occidentales:

Ha llegado el momento de explicarme. La única razón por la cual la Biblia tiene necesariamente que proponer una vida trasmundana, o vida después de la vida (con sus protocolos de acceso, sus instituciones, sus mecanismos de premiación y de ascenso social) es porque, previamente, ha hecho la condena radical de la pereza (madre de todos los vicios). La Biblia no está nada mal como código laboral. El mundo, para los apóstoles, profetas y demás delirantes que colaboraron en la redacción de ese código, no es sino un Mc Donald's. La fe hace al empleado del mes. Ha llegado el momento de explicarme. (76)

La pereza pone en riesgo el sistema de producción de la Biblia como Mc Donald's; es decir, de la «religión del capitalismo» o del «espíritu del capitalismo» regido por un ritmo irrefrenable de acción financiera, monetaria o laboral. ${ }^{6}$ Preferir no hacer nada no puede sino conducir a una parálisis del capital sostenido por la 
actividad incesante de las transacciones financieras o de las compras y ventas o del trabajo. Porque lo que se pone en juego con la pereza es, justamente, el sistema laboral: la mano de obra del sistema puede preferir no hacer nada como actitud política y eso, al fin de cuentas, es un peligro que debe contrarrestarse con una moral potente (la religiosa); o con una inmoralidad nacionalista (el evolucionismo racial y telúrico de Darwin). De ahí que la potencia revolucionaria de la pereza, justamente, se explica alejándose de esas tradiciones porque:

Deleuze, que junto con Toni Negri es de los mejores lectores de Spinoza, proclamó - $\mathrm{y}$ todavía hay gente que se niega a oír ese grito de batalla—: «Solo lo menor es grande y revolucionario». Para no hablar de otros revolucionarios perezosos. Yo, como Benjamin, «vine al mundo bajo el signo de Saturno, el astro de revolución más lenta, el planeta de las desviaciones y demoras». (80)

La revolución de la pereza consiste — no sin desparpajo- en su minoridad deleuziana en el centro de una cultura de la hiperactividad productiva que abre una potencialidad de futuro diferente a través de un ritmo enlentecido, desviado y demorado, tan saturnino y melancólico como aquél que declara Benjamin en la cita. Es una conceptualización de la pereza como derecho y potencia revolucionaria tal como la concibe el yerno de Marx, la oveja negra en la familia, Paul Lafargue (I880), quien proclamó en el siglo XIx que no es el trabajo el verdadero camino a la revolución, sino la pereza en tanto que el hecho de pasar el tiempo haciendo nada es lo que la burguesía ha conquistado paulatinamente, y es la lucha política que le compete al proletariado. Lejos de concebir el trabajo en el centro de la revolución utópica, es el derecho a la pereza el que podría cambiar el mundo horrible de súper explotación laboral al que eran sometidos los trabajadores en la modernidad sólida.

Pero en esa cita hay algo más: como en Benjamin, el carácter menor de la pereza no es posible sino como acción mínima a través de la escritura procrastinadora y, a veces, inconclusa. De ahí que la inacción de la pereza conlleve para el diarista la imposibilidad de escribir sobre la pereza si no es relatando la perezosa imposibilidad de escribir, relatando la inacción, poniéndola en discurso como forma de preferir no hacer nada salvo declarar que se prefiere no hacer nada, como Bartleby, otra vez. Es ahí, en esa potencialidad de la pereza que el futuro del pasado abre en el presente la infertilidad mallarmeana del silencio que se escribe, y es allí también, decimos, en que el mundo contemporáneo como actividad de la inactividad menor de la escritura perezosa es capaz de sostenerse un ritmo alterno y singular de actividad diferenciada de la irrefrenable proliferación activa del capital. La pereza, como la melancolía, es, así, una actitud política y estética de disonancia con el mundo y el presente Mc Donald horrible. ${ }^{7}$ Pero lo es, en tanto puesta en forma y escritura de su catástrofe, de su imposibilidad.

Esto es lo que le permite a Link diferenciar la pereza del ocio. Aunque permanezcan en constelaciones semánticas semejantes, frente a la tendencia a la misma 
nada que es la pereza, el ocio se ha convertido en una industria para el protagonista de «Parpadeos», en un Mc Donald con estructura de religión. En el ocio se decide escribir, no supone la inacción que conlleva la pereza. El ocio presupone hacer algo: ocupar el tiempo en pasar el tiempo, divirtiéndose. Lejos de la defensa del ocio que realiza Bertrand Russel o Fabián Casas, el diarista entiende que la pereza es más revolucionaria por su tendencia a la nada radical, y la nada es el lugar, ya lo sabemos por Nietzsche en Sobre verdad y mentira en sentido extramoral, no sólo de la indeterminación sino en el que son posibles todas las ficciones de la cultura. De este modo, si la melancolía en Los años 'go nacía por la muerte de la ficción, la pereza como tendencia a la nada no hace sino transformarse en una forma activa de la melancolía con la cual acercarse a esa nada donde se imaginan las ficciones.

La toma de posición por una pereza revolucionaria, también está presente en Fantasmas, aunque, prácticamente de una manera innombrada, cuando en «2007», Link postula que lo único seguro como real es la nada y que la pasión por lo real se debería proponer construir una diferencia mínima precisamente allí donde no hay nada. Lo que sigue en ese fragmento es un relato sobre la siesta animal y humana como productos, ambas, del «mal del sauce»: un sopor que invade y que Link rescribe en uno de los apartados de La mafia rusa. Justamente en esos momentos mínimos de nada, de una escritura sobre la nada y sostenida en la nada, es donde la pereza tiene su lugar. Escribir desde la pereza no es sino someterse a ese ritmo de interrupción de inacción en un mundo que constantemente requiere que abandonemos la pereza.

Pero en ese punto común entre La mafia rusa y Fantasmas, aparece, también, una nueva forma de pereza, la pereza intelectual, que genera presencia en Fantasmas y en Cómo se lee. Ese tipo de pereza, que adquiere una dimensión de ataque contra una actitud intelectual, no es, de ningún modo, la de preferir no hacerlo, sino la de no hacer algo por facilismo o simplificación, como atajo para seguir produciendo y sobrevivir en medio de un mundo laboral y profesionalizado. Es una pereza asimilada por el capitalismo. Nuevamente, entonces, se produce sobre una misma palabra la proliferación de sentidos diferentes que contradicen la unicidad del significante que se escribe.

Algo semejante sucede en Montserrat, cuando Manuel asegura:

Por alguna razón, me dejo dominar por la melancolía. Dudo que esta tarde trabaje en «las cosas pendientes». Aprovecharé para leer, después del gazpacho. A las 4, dijo B., pasa a buscar mesas y sillas para llevar a su terraza. La vida puede, en efecto, ser dulce. Pero es más frágil que nuestras plantas de maceta. (2006:I2)

El cuerpo se deja dominar por la melancolía y abandona el trabajo de las cosas pendientes, se deja, o prefiere, no hacer nada. Sin embargo, ese momento dulce, es frágil como una planta en una maceta. La vida y la actitud dulce, léase la pereza, es frágil para un profesor que tiene «una precaria situación económica» que lo «obligó siempre a disimular la pobreza (en primer término) y a multiplicar mis 
trabajos (en segundo lugar)»(36). Más allá de que la mutación es disimular la pobreza y no exponerla como en La mafia rusa, lo que aquí sucede es una variación de la relación entre melancolía y pereza, como si fuera un estado transitorio de alegría, frágil, que a duras penas se consigue en un mundo laboral exigente y capitalista. La preferencia de no hacer nada tiene, como vemos, alcances diferentes y hasta contradictorios con lo planteado en el libro posterior, aunque aún conserve la potencia de disonancia, así entendida, como preferencia de no hacer nada, con el mundo. Disonancias con el mundo que el melancólico alimenta.

Sucede que, como ha señalado Javier Gasparri, Link sostiene su performance en una forma de la "contra-dicción», que hace, incluso, escribir una novela sin novela como La ansiedad, destacando la potencia del arte como forma indeterminada donde los conceptos y las ideas devienen diferencialmente en la singularidad de un pathos, de un impulso inaprensible, aunque unívoco. Esa inaprensibilidad que, en un primer momento, parece desprenderse de una lógica de lo indeterminado traza una ética de lo indeterminado en la cual, cada término comienza a valer en su sentido de potencia futura y de devenir imaginario y, de este modo, la potencia de la escritura de Link reside en situarse en el umbral donde lo indeterminado se junta con la determinación para estallar y traspasar, incluso, ese umbral mismo en una proliferación diferencial sin fin. Si la proliferación de la melancolía y de la pereza son evidentes, todavía más lo son los sentidos que devienen en la escritura, pero sentidos siempre puestos a funcionar, lejos del capricho del desorden o de la renuncia a una toma de posición, como contra-dicciones que tienden a rescatar de cada palabra su potencialidad política y estética que se basa en la posibilidad de lo abierto, que no es otra que el umbral donde determinación e indeterminación se encuentran para hacer proliferar una multiplicidad radical. Las palabras proliferantes son sometidas a esa forma o modo de escritura que, vaciándolas aparentemente de sentido, las satura de él para demostrar que es justamente su heterogeneidad la que posibilita siempre una ética y una estética de la imaginación incesante que pueda mutar el mundo horrible de la determinación y del poder a partir de mundos mínimos y diferentes, pero sostenidos en la lógica melancólica de la disonancia con el mundo decadente.

Como sostuvimos, Ritvo señaló que el salto entre polos diferentes y contradictorios es característico del temple melancólico. ¿Alcanza esto para sugerir que Link es un melancólico? Si Link, como ha señalado Mario Bellatín, es un performer impostor, o, como indica Alberto Giordano, es aquél que se cuida en algunas performances de decepcionar al lector-auditor declarando abiertamente el carácter ficcional de su escritura, por eso mismo, resultaría difícil definir a partir de la máquina de su escritura indeterminada y contradictoria su carácter melancólico. Aunque lo que tenemos es justamente esa máquina, esa escritura de la impostura y, por ende, sí podemos conjeturar, más allá de sostener la duda sobre la melancolía del autor, que la escritura de Link, la forma que diseña, saltando entre contra-dicciones en torno de unas palabras y conceptos, se construye como un discurso de la interrupción y tiene la estructura de una imaginación melan- 
cólica. Esto supone retomar y desandar las mismas definiciones de Bellatín y de Giordano, además, para encontrar en ellas claves de una melancolía que opera en diferentes niveles, en la escritura y, por ende, en la vida también.

En Melancolía y verdad, Frédéric Peillon asume una revisión de la postura psicoanalítica sobre la melancolía, considerando no sólo la historia y el devenir del término y sus significados, sino, además, quitándole el sesgo de mera patología con que suele circunscribirse el carácter melancólico. Asegura, de este modo, que el problema central del melancólico consiste en su capacidad especial de designar la parte de inconsistencia que toda verdad encubre, aun con el riesgo de perderse en ella. De este modo, el melancólico se haría cargo de la potencia de la afirmación negativa de que «todo lo que digo es falso». Esa afirmación negativa aproximaría al melancólico a las paradojas del mentiroso, puesto que desnudaría una falsificación sin retorno y que no deja nada en pie; incluso, si ese enunciado mismo es también falso como parte del todo, puede sostenerse con él lo contrario. Lo cierto es que en tal enunciado, todo está afectado de la misma artificialidad. Por ende, es comprensible por qué Link postula la imaginación (melancólica) como pieza central que trata de conjurar la muerte de la ficción, porque no se trata en su narrativa de la oposición metafísica entre realidad/irrealidad, verdad/mentira, sino de la construcción de un umbral operativo donde esas dicotomías pasan a funcionar juntas, resaltando todo el tiempo la artificialidad/falsedad del procedimiento, pero lejos de estar esta misma artificialidad/falsedad en una mera oposición con la naturalidad del dandy melancólico moderno como Oscar Wilde o Charles Baudelaire (Bourriaud), ya que la artificialidad es la naturalidad misma de la escritura y, por eso mismo, el umbral que sostiene la imaginación. La falsedad/artificialidad es la naturalidad y la verdad de la escritura y, por eso, se abre allí una indeterminación máxima, puesto que esas afirmaciones negativas que hemos seńalado respecto de Link, como las de «imaginarse» una infancia pobre para recuperar el momento de su pérdida, resaltando la artificialidad de su yo, y quedando, así, relegado, casi a una máscara, no hacen sino señalar la verdad de la melancolía en su escritura. No se trata, entonces, de un mero coqueteo con la tradición, sino de un uso de todos los significados que esa tradición melancólica conlleva para ponerlo a funcionar como máquina que evita someter a duelo la muerte de la ficción en la vida del presente. ${ }^{8}$

\section{Circulaciones}

La mayoría de los textos que constituyen La mafia rusa fueron publicados originalmente en internet, en suplementos culturales y/o en revistas como formas breves y mínimas. ${ }^{9}$ La mayoría de los libros de Link están compuestos por artículos o fragmentos cuyos orígenes son los márgenes amplios del ciberespacio o de las publicaciones periódicas. El caso de Montserrat también es significativo, ya que aparece por entregas en Linkillo, y luego es publicado como blogonovela. Esa articulación con espacios virtuales, pero también periodísticos de publicación, algo que en la actualidad es central por su colaboración permanente en Perfil, con el soporte libro, adquiere relevancia en Cómo se lee, cuando Link defiende 
la potencia de la web para generar un espacio de democratización. Claro que, como sabemos, esa democratización es, en principio, restringida a la posibilidad de acceso y, en segunda instancia, algo que ya resonaba en ese libro de Link, a una política de acceso abierto que en los últimos años ha sido puesta en cuestión con los innumerables cierres de páginas y persecuciones judiciales que buscan defender los derechos de copyright (Megaupload, por ejemplo). La escritura de Link podría leerse como una política de apertura hacia ciertos espacios amplios en los que ha circulado la escritura letrada —el periódico - en una tensión conflictiva, al menos desde el modernismo, entre practica literaria y periodística.

Lo que interesa leer es, sin embargo, qué presuponen esas circulaciones para una escritura perezosa de la melancolía. Me detendré en la potencia de publicación en la web, ya que es la que suele suscitar reparos, pero sobre todo, porque Link mismo declaró en entrevistas que todo lo que escribe ha pasado, previa o posteriormente, por su blog. En principio, puede parecer que esa elección responde a un mero carácter de actualidad tecnológica de la escritura, una adhesión a un soporte novedoso, lo que haría sospechar de una mera sumisión a la actualidad. Sin embargo, Link ha sido claro en varias oportunidades:

Pensaba (y pienso) que los mecanismos de publicación en línea nos permiten recuperar géneros muy investigados en el pasado (el folletín, por ejemplo, en el siglo XIx) y que no habría hoy manera de desarrollar en otro soporte (antes, en La ansiedad, había intentado sostener un melodrama epistolar a través de chats y correos electrónicos). (2009a:I)

Antes que un formato actual, el blog, en Link, se escribe como un espacio que permite hacer sobrevivir — no repetir — algunos gestos de publicación de la práctica escrita; es un espacio que genera un anacronismo para la práctica en la medida en que recupera la posibilidad de escribir por entregas, que en la prensa de hoy es difícil de sostener, salvo en las columnas de opinión, en las que Link participa. El uso del blog es una forma melancólica que hace sobrevivir, entonces, ruinas del pasado reelaboradas en el presente bajo la forma del post. Lejos de sumirse a la actualidad, el blog produce la apertura futura del pasado a través del presente: genera una estratificación de temporalidades que altera el orden del tiempo mismo. El blog, como declara en 2009, incluso, es un anacronismo en sí mismo frente a Facebook — que para Link carece de relevancia_- Lo interesante, además, es cómo piensa la articulación con el formato libro. Pensado como bitácora o cuaderno de escritura, el blog:

si ahora llega al libro es porque una segunda lectura de esos textos me permitió rescatar aquellos que menos ligados estaban a una coyuntura específica y organizarlos en cinco apartados que coinciden parcialmente con las «etiquetas» que llevaban en el blog.

Son textos, podría decirse, sobreeditados: ninguno ha permanecido exactamente igual a como fue escrito en principio y, sobre todo, han migrado para formar algo así como una argumentación espasmódica. 
¿Cambian esos textos, ahora que llegan a la forma libro? Creo que su acumulación más o menos insensata (es decir: cronológica) en un blog pretendía salvarlos del destino perecedero (los diarios viejos sólo sirven para envolver los huevos). Pero es el libro donde cualquier cosa que uno escribe adquiere una dimensión diferente. No sé por qué.

O lo sé, pero no entiendo el fenómeno: no hay crítica de producciones escritas diferentes del libro. No hay crítica (literaria o filosófica) de producciones en otro soporte diferente del libro. Ni siquiera los estudios culturales han conseguido sacar a las ediciones digitales de la mera curiosidad de época, la «novedad». De modo que la cultura va muy por delante de las disciplinas críticas, que se pierden la posibilidad de intervenir en relación con el presente. (Link 20I2)

Lejos de la melancolía airana de hacer sobrevivir la publicación de libros en un momento donde el libro está por desaparecer, que enuncia en "Ars narrativa», Link plantea que el libro aún sostiene una potencia que no entiende bien qué es frente a las publicaciones virtuales. Es decir, hay un cierto carácter aurático residual en el libro que aún hoy genera insistencia frente a las publicaciones críticas en formatos que no sean en papel. Es el año 2012 cuando escribe esa sentencia. ¿Qué leer en esa respuesta que sin embargo desafía publicando prolíficamente fuera y dentro del soporte libro? ¿Un juego por la innovación o una provocación a la hegemonía de la cultura del libro de la que él tampoco reniega? Lo que se lee, sostenemos, es la impugnación de lo actual a partir de lo actual. Mientras que lo actual, en un sentido común, podría ser leído como el blog o internet, para Link, lo actual es la resistencia de la crítica académica al blog como tecnología que ya en 2012 es anacrónica y obsoleta frente a la explosión de las redes sociales. Es decir, lejos de pensar el blog como una apuesta actual, Link sostiene que es sólo allí donde ciertos anacronismos pueden imaginarse melancólicamente como supervivencias —el caso del folletín - y que la resistencia a esa forma de publicación es lo que verdaderamente constituye la actualidad perezosa de cierto sector del campo crítico y académico que sólo recientemente se ha abierto a considerar a algunas publicaciones virtuales como valiosas y ha generado, a cuentagotas, mecanismos de evaluación para las mismas.

Pero hay algo más que debe leerse en ese empleo y apelación de las tecnologías de la información. Si, como sostiene en Fantasmas, hay que hacer oídos sordos a la muerte de las vanguardias y, por ende, del arte; es decir, hacer oídos sordos para evitar su duelo, se vuelve necesario ensayar e imaginar alternativas que permitan su supervivencia como futuro pasado en el presente. ¿Por qué no ver en esa articulación entre tecnologías masivas y escritura, la pregunta aún insistente, de la posibilidad de lo aurático y de la experiencia en el arte del presente, en un devenir melancólico de las preocupaciones que Benjamin ensayaba en la década del 30 a propósito de la reproductibilidad técnica del cine, hoy devenida reproductibilidad digital? Es decir, ¿cómo no ver en esa articulación un anacronismo que atraviesa la actualidad promoviendo un desarreglo temporal en la misma actualidad de las «nuevas tecnologías»? ¿Cómo no ver, también, la insistencia 
sobre las posibilidades de articular tecnología, vida y arte tal como lo pensaron movimientos de vanguardia a partir de la técnica industrial como el futurismo o el dadaísmo de comienzos de siglo, pero sin considerarse ya vanguardista? No se trataría de la mera reproducción de la vanguardia histórica como un canon del arte del siglo xx, sino de la posibilidad de imaginar melancólicamente un camino aún posible de la potencia de la vanguardia en el mundo actual, que nunca puede ser ya, hoy, el mundo de la vanguardia. En este sentido, ¿cómo no ver la preocupación, no por la novedad del mercado o de la tecnología, sino de lo nuevo como lo históricamente necesario frente a la tecnologización social?

Link advierte, en la misma entrevista citada, que esa inminencia imaginaria como forma activa en el formato blog no debe entenderse como una defensa a ultranza del mismo. Se trata, para el autor, de una forma menor que adquiere toda su centralidad en la posibilidad lamborghiniana de primero publicar, después escribir, pero que no basta, ni debe ser entendida como un sistema de normalización de las prácticas del presente, sino como una alternativa que traza relaciones múltiples, aún hoy, con los formatos tradicionales del libro en papel. Este sistema de publicación que estratifica temporalmente su consistencia, por ende, no deja de revelar su melancolía por el libro como objeto aurático en el que se insiste, todavía hoy, a pesar de estar puesto en crisis en el presente como canal hegemónico de circulación de la palabra escrita.

Sin embargo, tal insistencia es reelaborada. Para comprender esto, debemos partir de la afirmación de que la lectura del dispositivo de circulación de Link, multisoporte, conflictúa cualquier posición asumida desde una mera distancia con lo actual, que no sólo supone el sostén de una jerarquía esteticista (lo alto/lo bajo), sino que se deifica a sí misma cosificando y reproduciendo una categoría funcional a la modernidad del capital para leer prácticas contemporáneas. En Profanaciones, Agamben establece que la distancia entre lo humano y lo divino se reproduce en la lógica del capital como separación entre el trabajo manual e intelectual, y entre el trabajo y la mercancía. Por ende, la distancia es funcional a la actualidad del capitalismo. Por eso, para contrarrestar esa distancia que deifica y separa las cosas de los hombres y del mundo material en una esfera fetichizada/divinizada, Agamben propone la categoría de uso, que supone, no ya la distancia, sino la posibilidad de manipular política y desviadamente los objetos de la religión capitalista deificados y distanciados por sí y en sí de los hombres. Es decir, profanar lo improfanable. Habría, entonces, que leer la escritura en las plataformas virtuales de Link como un uso de las mismas puesta a funcionar en una lógica ajena, que es la de la escritura (y habría que agregar, crítica- literaria). Una plataforma que funciona no sólo para contar historias, sino para garantizar la circulación más amplia de aquello que forma parte o que terminará en un libro, objeto artístico doble, mercancía y significación, si recordamos a Bourdieu. En este sentido, la circulación por internet supone una deflagración del valor de cambio del libro respecto del valor de uso y de circulación. Es decir, una alteración no sólo de la lógica capitalista, sino, además, del libro como mercancía cuyo 
valor de cambio es también alto. La circulación en internet no es gratuita, pero el valor económico es mucho menor que la del libro impreso. Por ende, lo que se altera es el valor económico de la escritura que se deflaciona en el formato web, mediante una mayor circulación y, por ende, una capacidad simbólico-cultural menos dependiente de su valor económico.

Este modo de circulación, al mismo tiempo, es correlativo del uso de las formas breves, casi posts, o, muchas veces, similar al de los géneros típicos de las nuevas tecnologías. Lo cual repone una fantasmagoría $p o p$ que opera en los modos de escribir y de circular de Link. Sabemos que el uso del lenguaje publicitario o de los medios masivos por el arte pop tuvo y tiene una potencialidad indeterminada que sigue y seguirá suscitando la polémica y el desacuerdo. Ana Longoni sostiene que las posiciones sobre el pop pueden distinguirse entre quienes lo rechazan como una burda mercantilización de lo artístico, y quienes consideran que el pop genera una crítica a la cultura consumista. Esta situación dicotómica de la crítica del pop art, que señala Longoni, me parece el lugar desde donde se puede considerarlo como uso del repertorio masivo y publicitario con carácter profanatorio y, por ende, generador, en sí mismo, de esa paradojal situación respecto de las lecturas que de él se realizan.

Se podría pensar el pop art como una práctica que apela al uso de un repertorio publicitario o masivo, pero con un carácter profanatorio dentro de una forma capitalista improfanable. Sería, de este modo, una manera de hacer trabajar a la mercancía, de restituirle un uso que su valor de cambio eclipsa y opaca, desviando el uso del mero consumo mercantilista. Es por este motivo que el pop puede entenderse como un modo de retorno traumático de lo real, como sostendrá Hal Foster, o sea, un fallido del mundo mercantilizado que sólo puede ser repetido para tamizar lo real entendido como traumático; pero, por esto, que en su misma repetición rompe el tamiz-pantalla de la repetición. Así, el trauma de la mercantilización se vuelve posibilidad de hacer algo con ella, de desviarla de su telos consumista a partir de su repetición no como reproducción sino como uso. Es, en este sentido, que debe leerse el planteo de Andrea Huyssen, cuando asegura que, en los 60, «con el arribo del pop, el arte se hizo profano» y provocó que: «Aun en las condiciones impuestas por la industria cultural capitalista y su aparato de distribución, el arte puede en última instancia abrir caminos liberadores en virtud de su autonomía e inutilidad práctica» (264). Porque en virtud de su inutilidad generó con la mercancía algo que se le distingue, la cambió de su finalidad utilitaria única, que es la del imperativo del valor de cambio.

En Fantasmas, Link asegura que la imaginación pop es otra de las alternativas que supone que sólo hay presente y que el futuro y el pasado son ilusorios. Sin embargo, ese fantasma del pop que usa una forma del presente, lo hace para desprenderse, de todos modos, en el devenir de la escritura de Link, de la abolición del pasado y del futuro a partir de una estratificación temporal melancólica. Porque si el pop es un fantasma, eso quiere decir que la melancolía, como umbral de desarreglo temporal por donde pasan los fantasmas, lo transforma en algo que es 
y no es ya el pop de los 6o. De ahí que, dentro de la escritura de Link, el pop sea reelaborado en otra dirección que sí se presenta como una alternativa para seguir escribiendo. ${ }^{10}$ Porque el uso de las formas breves, muchas veces con la forma propia de la cibercultura, puede leerse como una materialización de la necesidad y pobreza del trabajo de los escritores que aparecen en el terreno de la ficción. Es decir, como un trabajo menor y perezoso para sobrevivir con la práctica de la escritura en un mundo tecnologizado. Las formas mínimas, ensayísticas, o ficcionales, desarticuladas y fragmentarias, dan cuenta de una resistencia de la escritura a su propio devenir en el trabajo del escritor. Incluso el ritmo de la ficción publicada de Link, cuatro libros en más de diez años, es significativo de una procrastinación que parecería operar en el modo en que se escribe y se presentan escribiendo los escritores de la ficción. Una forma de trabajo artístico que, según Bauman (2000), corresponde a la modernidad sólida y que aquí perdura como ruina fantasmática conflictuada con la temporalidad también fantasmática del pop.

Es este modo particular de trabajo, lo que habilitaría pensar en la melancolía perezosa de Link en una misma constelación con la procrastinación de La novela luminosa de Mario Levrero. Sólo que si la escritura de la imposibilidad de escribir la novela, que puede vincularse con la imposibilidad de escribir la nota en «Parpadeos», termina en una escritura excesiva y extensa en el caso de Levrero, en Link, el resultado son formas breves. Por otro lado, al mismo tiempo que la procrastinación se enuncia en la brevedad narrativa y en la poca publicación en formato libro, ésta contrasta con la enorme multiplicidad de las textualidades de Link en la web y en la prensa y en diferentes formatos que luego, después de un proceso de decantación, selección y retoques, a veces, terminan en libro. Es decir, la procrastinación está articulada con una superproductividad logomaníaca más allá del formato libro editado, cuestión que es impensada en Levrero. Por ende, en Link se trata de la convivencia de textualidades en soportes dispares puestos a circular y a trazar trayectorias y ritmos diferenciales entre sí que estratifican fantasmas del pasado en su presente futuro. Son formas que se inscriben y se desmarcan de diferentes mercados, alterando, con ello, las primacías de los valores, de uso y de cambio, según esas inscripciones.

De modo que los saltos entre formatos diferentes, así como la tensión entre esos ritmos de escritura parca y proliferante, dan cuenta de que el dispositivo de escritura de Link se sostiene por la interrupción y el salto entre polaridades dispares propias del discurso melancólico, que conflictúa cualquier relación directa con la actualidad. Como el ángel melancólico en el cuadro de Durero —una figura medieval - se encuentra hundido y apático en el gabinete de su presente — renacentista—, grávido y con la mirada que no deja de atisbar aquello que se mueve, allá, en la ventana distante del paisaje monstruoso, así, la escritura de Link se quiebra también en ese umbral donde las temporalidades y las contradicciones, propias de un discurso melancólico, irrumpen en la escena de la imaginación contemporánea. Y eso es también, lo que aún puede ese devenir incesante de la escritura en el presente mercantilizado. 


\section{Notas}

${ }^{1}$ La imaginación de la catástrofe muta a lo largo del texto, también, en contradicciones tanto en su definición como en su adhesión o no a ella. Pero aparece, dentro de ese imaginario, fácil de percibir en la blogonovela Montserrat, una persistente asociación a la melancolía como uno de sus avatares. Por ejemplo, en el apartado sobre El principito: «ese estado hiper que se identifica con la infancia es irrecuperable por cualquier otra vía y por eso equivale al malestar de lo moderno y la melancolía por lo que se ha perdido irremediablemente (imaginación de la catástrofe)» (Link 2009b:I73). En este caso, el sentido de la melancolía se fuga y no es fácil de determinar si allí la melancolía es una añoranza o un trabajo sobre la ruina de la infancia para hacerla devenir futuro. Se puede tratar, en este caso, de una nueva inflexión de la melancolía: un umbral entre las posiciones previas, que abriría su devenir semántico a una diferenciación sin fin. Nos detendremos, sin embargo, en los otros dos sentidos explorados, porque es esa tensión la que aparece en La mafia rusa.

${ }^{2}$ La sospecha se funda, en primer lugar, en el uso de la imaginación como forma de la melancolía que el propio Agamben explora en su libro Estancias y porque, en un juego ficcional, el remitente Daniel Link en Fantasmas parece dialogar con un destinatario cuyo nombre es Jorge. La forma pareciera la de una respuesta imaginaria en una correspondencia entablada con un Jorge que puede ser el propio Agamben, españolizado, o Jorge Panesi, a quien Link vindica como maestro en varias oportunidades. Lo interesante es el dispositivo melancólico de la correspondencia puesta en juego en el texto, que reactualiza un género epistolar en el presente, así como la indeterminación abierta por el destinatario y la coincidencia de una teoría entre imaginación y melancolía, que el propio Agamben abre a partir de la tradición occidental clásica, benjaminiana y psicoanalítica, coordenadas que insistentemente son revisitadas por Link cada vez que se enuncia la palabra melancolía en su escritura, tal y como señalo en este artículo.

3 Giorgi y Rodríguez sostienen que la vida emerge como desafío y exceso de lo que nos constituye como humanos socialmente legibles y políticamente reconocibles.

${ }^{4}$ En Fantasmas, Link sostiene que: «La Dialéctica (y aquí dialéctica significa tanto el título de un libro como un método) analiza un dispositivo fatal de seducción y encantamiento, sostenido en figuras o fantasmas (monstruos, inclasificables o desclasificados) que, ahora sí, no puede sino definir, atravesándolo, lo imaginario» (2009b:27). Esa vida que se hace por la imaginación, es la de su fantasma de pobre, por eso, su desclasificación de o, al menos, su monstruosidad como pobre real/inventado. Porque la imaginación en Link es el lugar del umbral por donde pasan todos los fantasmas, entes/seres que son y no son al mismo tiempo. Las palabras —en este caso, melancolía y pereza-, como fantasmas que atraviesan el umbral de lo imaginario son y no son al mismo tiempo, como veremos, sentidos oscilantes.

${ }^{5}$ Pero que anteriormente aparece, como señala link en «Noticia sobre el origen de los textos», en Latido en febrero de 200 .

${ }^{6}$ Este panorama se desprende del libro de Agamben, Profanaciones, donde plantea que el capitalismo es la religión contemporánea que tiende a separar las cosas del uso de lo humano, para subsumirlas a todas a su valor de cambio. Chiapello y Boltansky plantean que el nuevo espíritu del capitalismo asimila en su lógica incluso a sus instancias críticas, lo cual no presupone, ciertamente, una esterilidad del pensamiento o el arte crítico, como lee la propuesta Rancière en El espectador emancipado, sino que lo obliga a replantear sus estrategias. En Mundo consumo, Zigmunt Bauman arriesga un diagnóstico similar, y propone la necesidad de insistir en planteos que no permitan la burocratización capitalista de las prácticas artísticas que se convierten de día en día en más funcionales al establishment global de las gestiones políticas basadas en la promoción artística.

${ }^{7}$ Starobinzki sostiene, en La melancolía en el espejo, que la melancolía se presenta en Baudelaire como una forma activa frente a un mundo horrible. Ritvo, por su parte, sostiene que la actividad melancólica del decadentismo consiste en una actitud esteticista, la de extraer el esplendor en la ruina; es decir, la de transformar en potencia (en ese caso estética) un mundo convertido en cadáver.

${ }^{8}$ Ya sabemos, por otro lado, que ese mismo término, en la literatura argentina es un umbral que, desde «El concepto de ficción» de Juan José Saer problematiza las 
clasificaciones y abre una zona de incertidumbre e indeterminación que supera la oposición con la realidad, el realismo y la verdad de ese concepto. Por ende, no es inocente el uso que hace de él Daniel Link.

${ }^{9}$ No me detendré en el carácter de blogonovela de Link, o en el uso estético de las nuevas tecnologías que puede desprenderse de sus libros como diferencia o no con el Net.ar. En parte, porque ese trabajo ha sido realizado ya por Norma Carricaburo en su libro Del fonógrafo a la red, pero fundamentalmente, porque me interesa pensar la relación que Link genera con el mercado a partir del uso de las plataformas virtuales, algo que ha sido poco abordado. Es decir, me interesará considerar su web art 2.o como generador de una singular forma de circular. Sobre las diferencias entre Net. ar y web art 2.0, véase: José Luis Brea, El arte post media.

${ }^{10}$ Esto es claro cuando Link lee a Susan Sontag. Allí sostiene: «Sontag encuentra en la imaginación pop unos fantasmas que vienen de otra parte» «La cultura pop, podría pensarse, es un vehículo que potencia las ondas mnemónicas» «Y aunque, por lo general, ese cine responda a las necesidades de expresión de una unidad del capitalismo (la tecnofilia), entendido como dispositivo de captura, en esas películas sencillas "acechan las más profundas angustias por la existencia contemporánea” (2009b:98).

\section{Bibliografía}

\section{Corpus}

Link, Daniel (200I). Los años 'go. Buenos Aires: Adriana Hidalgo.

(2003). Cómo se lee y otras intervenciones críticas. Buenos Aires: Norma.

(2006). Montserrat. Buenos Aires: Mansalva.

(2008). La mafia rusa. Buenos Aires: Emecé.

(2009a). «Guat pass'» [en línea] N. Revista de cultura. Consultado el 25 de abril

de 2015 en http://linkillo.blogspot.com.ar/2009/o4/guat-pass.html

(2009b). Fantasmas. Buenos Aires: Eterna Cadencia.

(2010). «Facebook y yo» [en línea]. Linkillo. Consultado el I4 de noviembre de 20Io en http://linkillo.blogspot.com.ar/20Io/ıI/facebook-y-yo.html

(2012). «Del diario al blog, al libro». Linkillo. Consultado el 8 de agosto de 2012

en http://linkillo.blogspot.com.ar/20I2/o8/del-diario-al-blog-al-libro.html (2013). Exposiciones. Buenos Aires: Blatt \& Ríos.

\section{Otras obras literarias}

Casas, Fabián (2008). Ocio. Seguido de Los veteranos del pánico. Buenos Aires: Santiago Arcos. LeVrero, Mario (2008). La novela luminosa. Buenos Aires: Mondadori.

\section{Teoría y crítica}

Adorno, Theodor (1970). Teoría estética. Barcelona: Hyspamérica, 1984. Traducción de Fernando Riaza.

Agamben, Giorgio (1977). Estancia. La palabra y el fantasma en la literatura occidental. Valencia: Pretextos, 1995. Traducción de Tomás Segovia.

(2005). Profanaciones. Buenos Aires: Adriana Hidalgo. Traducción de Flavia Costa

y Edgardo Castro.

Aira, CéSAR (1994). «Ars narrativa». Mimeo. 
Aristóteles «Problemata XXX», en Raymond Klibansky y otros, 1989. Saturno y la melancolía. Madrid: Alianza, 2006. Traducción de María Luisa Balseiro.

Barthes, Roland (1971). Sade, Loyola, Fourier. Caracas: Monte Ávila. Traducción de Néstor Leal.

Benjamin, Walter (1928). Origen del drama del barroco alemán. Madrid, España: Taurus, I99I. Traducción de José Muñoz Millanes.

Iluminaciones II. Madrid: Taurus, 1972. Traducción de Jesús Aguirre.

Bauman, Zygmunt (2000). Modernidad líquida. México: Fondo de Cultura Económica, 2003. Traducción de Mirta Rosemberg.

(2008). Mundo consumo. México: Fondo de Cultura Económica. Traducción de Albino Santos Mosquera.

Bellatin, Mario (2013). «Antiprólogo», en Daniel Link. Exposiciones. Buenos Aires: Blatt \& Ríos.

Boltansky, Luc y Eve Chiapello (1999). El nuevo espiritu del capitalismo. Barcelona: Akal, 2002. Traducción de Marisa Pérez Colina y otros.

Bourdieu, Pierre (1992). Las reglas del arte. Génesis y estructura del campo literario. Barcelona: Anagrama, 2005. Traducción de Thomas Kauf.

Bourriaud, Nicolás (1999). Formas de vida. El arte moderno y la invención de sí. Murcia: Cendeac, 2009. Traducción de Carmen Rivera Parra.

Brea, José LuIs (2002). La era postmedia: acción comunicativa, prácticas (post)artísticas. Salamanca: Centro de Arte de Salamanca.

Burton, Robert (I62I). Anatomía de la melancolía. Buenos Aires: Espasa Calpe, 1947. Traducción de Antonio Portnoy.

Canala, Juan (20I4). «La escritura y la máquina: La narrativa de Daniel Link». Mimeo.

Carricaburo, Norma (2008). Del fonógrafo a la red. Buenos Aires: Circeto.

Danto, Arthur (1997). «Arte pop y futuro pasado». Después del fin del arte. Buenos Aires: Paidós, 2012, I4I-I58. Traducción de Elena Neerman Rodríguez.

Deleuze, Giles y Félix Guatari (1980). Mil mesetas. Buenos Aires: Pretextos, 2006. Traducción de José Vázquez Pérez.

Foster, Hal (1996). El retorno de lo real. Madrid: Akal, 200I. Traducción de Alfredo Botnos Muñoz.

Freud, Sigmund (I9I7). "Duelo y melancolía» [en línea]. Derrida en castellano. Consultado el 23 de abril de 2015 en https://www.academia.edu/9594009/Derrida_en_castellano

GASPARRI, JAVIER (20I3). «Las aventuras (in)formales de Linkillo. La realidad como invención», en Sandra Contreras. Realismos, cuestiones críticas. Rosario: Fhumhyar, 179-208.

Giordano, Alberto (2008). El giro autobiográfico de la literatura argentina actual. Buenos Aires: Mansalva.

Giorgi, Gabriel y Fermín Rodríguez (20II). Ensayos de biopolitica. Excesos de vida. Buenos Aires: Paidós.

Huyssen, Andrea (1986). «La política cultural del pop». Después de la gran división. Buenos Aires: Adriana Hidalgo, 2006, 306-372. Traducción de Pablo Gianera.

Lafargue, Paul (1880). El derecho a la pereza. Buenos Aires: Longseller, 2003. Traducción de Antonio Tulián.

Longoni, AnA (2004). «Oscar Masotta: vanguardia y revolución en los sesenta». Oscar Masotta. La Revolución en el arte. Buenos Aires: Edhasa, 4-29. 
Nietzsche, Friedrich (I873). «Sobre verdad y mentira en sentido extramoral». Obras Completas. Vol. I. Buenos Aires: Prestigio, 1970, 543-556. Traducción de Juan Luis Vermal y Joan B. Llinares.

PANOfsky, IRWin y otros (1989). Saturno y la melancolía. Madrid: Alianza, 2006. Traducción de María Luisa Balseiro.

Pellion, Frédéric (2000). Melancolía y verdad. Buenos Aires: Manantial, 2003. Traducción de Horacio Pons.

RANCIÈRe, JaCQues (2008). El espectador Emancipado. Buenos Aires: Manantial, 20II. Traducción de Ariel Dilon.

Ritvo, Juan (2006). Decadentismo y melancolía. Córdoba: Alción.

Russel, Bertrand (1932). «Elogio de la ociosidad» [en línea]. Universidad Complutense de Madrid. Consultado el 25 de abril de 2015 en http://pendientedemigracion.ucm.es/info/bas/ utopia/html/russell.htm

Sontag, Susan (1980). Bajo el signo de Saturno. Buenos Aires: Debolsillo, 2007. Traducción de Juan Utrilla Trejo.

Starobinski, Jean (1990). «La melancolía ante el espejo. Tres lecturas de Baudelaire». Debats $33,75-88$.

ŽıžEK, SLAVOJ (2002). ¿Quién dijo totalitarismo? Cinco intervenciones sobre el (mal)uso de una noción. Madrid: Pretextos. Traducción de Antonio Gimeno Cuspinera. 